\title{
Effect of concentrated energy of laser beam on polymer material
}

\author{
Libuše Sykorová ${ }^{1, *}$, Vladimir Pata $^{1}$, Milena Kubišová ${ }^{1}$, and Jana Knedlová ${ }^{1}$ \\ ${ }^{1}$ Tomas Bata University in Zlin, Faculty of Technology, Department of Production Engineering, \\ Vavrečkova 275, 76001 Zlín, Czech Republic
}

\begin{abstract}
The article deals with the area of non-conventional technologies, specifically with the effect of concentrated radiant energy on the polymer material. There was studied the laser beam and its application to two different types of polymeric materials in details. PMMA, as a representative of the amorphous polymers and POM, which is a crystalline polymer, were used for experimental cutting as they frequently applied in industrial practice. The input technological parameters were changed during machining followed by evaluation of their interaction with the concentrated radiant energy of the laser beam. The results were subjected to statistical processing.
\end{abstract}

\section{Introduction}

The limiting factor of the level of the engineering production is the applied technology as it sets demands on energy consumption and thus determines the production energy intensity, raw material consumption and rate of their utilisation. Next, it also specifies practical, utility, and commercial characteristics of the products, thus it conditions the development of all industrial sectors.

The current production level requires the applied materials to meet the most demanding criteria in terms of a long durability, wear or economics. High demands on process ability of these materials are solved by the application of non-conventional technologies as the standard methods often do not meet requirements on speed and quality of the production. Therefore, the methods by which the better results in a shorter time are reached are used, especially laser machining [1].

This technology is highly accurate, fast, low-tech and ecological with high productivity and production efficiency. In this way, a laser is an optimal tool due to its properties. The laser beam can be applied to almost all kinds of material processing. Achievable dimensions of the structures depend on the type of laser, its parameters and material.

Laser cutting of material is affected by a variety of factors. The result of the optimisation process is to evaluate the impact of individual factors. It is necessary to emphasise the major effects, neglect less important once and generally to be able to set the parameters of the laser device so that the product capabilities are maximised [2].

\footnotetext{
${ }^{*}$ Corresponding author: sykorova@ft.utb.cz
} 


\section{Experiment}

\subsection{Preparation of specimen}

From the obtained scientific knowledge it follows, that the character of surface machined by laser depends among others on the thermal conductivity of the polymer. Therefore, it was decided to test two different kinds of polymers, namely amorphous PMMA and crystalline POM. Commercial CO2 laser Mercury L - 30 by firm LaserPro, USA was used for cutting of specimens. Changing power and feed rate of the laser system is possible. Ray of the laser could be focused on Mark diameter $d=185 \mu \mathrm{m}$. The laser is cutting with the software help of Corel Draw.

\subsection{Machining of specimens on the CO2 Laser Mercury L - 30}

The desired symbol was created in program Corel Draw, the width of the slot was $2 \mathrm{~mm}$ in all cases. Cutting parameters (output power and feed) were set, and these were changed gradually. Values of power and feed are presented as percent's from maximum power $(\mathrm{P}=$ $30 \mathrm{~W}$ ) and maximum feed (fmax $\left.=1066 \mathrm{mms}^{-1}\right)$ in charts of parameters combination and graphs. These specimens were prepared from this sheet (proportions 130 x $61 \mathrm{~mm}$, thickness $10 \mathrm{~mm}$ ). The edges were milled and grinded.

Table 1. Adjusted parameters of machining

\begin{tabular}{|c|c|c|c|c|c|c|c|c|}
\hline Percentage rate of feed f [\%] & 50 & 70 & 100 & & & & & \\
\hline Percentage rate of laser power P [\%] & 10 & 20 & 30 & 40 & 50 & 60 & 70 & 80 \\
\hline
\end{tabular}

\subsection{Dimension and profiles measuring of machined slots}

Dependence of slot depth on the laser parameters - output power and feed - was measured. The dimension measuring of machined slots was realised on the optical microscope ZEISS 2772. Suitable microscope optics which ensured $117 \mathrm{x}$ enlargements was set first of all. For the reason of statistical evaluation of measured values, the measurement of depth was realised in all slots five times. Slot depth $(\mathrm{d}$ in $\mu \mathrm{m})$ in dependence on laser parameters combination is presented in following results tables. See Table 2, Table 3 and Table 4. Values of power and feed are shown as percent's from maximum power $(\mathrm{P}=30 \mathrm{~W})$ and maximum feed $\left(\mathrm{fmax}=1066 \mathrm{mms}^{-1}\right)$ in charts of parameters combination and graphs. Description 20/70 means $20 \%$ value from power $30 \mathrm{~W}$ and $70 \%$ value from maximal feed $1066 \mathrm{mms}^{-1}$. These experimental results were evaluated and depicted in the graphs.

Table 2. Slot depth in $\mu \mathrm{m}$ for POM

\begin{tabular}{|c|c|c|c|}
\hline $\mathrm{P}(\%)$ & $\mathrm{d}(\mathrm{um}) \_\mathrm{f}(50 \%) \_\mathrm{POM}$ & $\mathrm{d}(\mathrm{um}) \_\mathrm{f}(70 \%) \_\mathrm{POM}$ & $\mathrm{d}(\mathrm{um}) \_\mathrm{f}(100 \%) \_$POM \\
\hline 10 & 29 & 18 & 11 \\
\hline 20 & 69 & 22 & 17 \\
\hline 30 & 87 & 55 & 28 \\
\hline 40 & 128 & 76 & 50 \\
\hline 50 & 150 & 92 & 72 \\
\hline 60 & 184 & 105 & 81 \\
\hline 70 & 195 & 143 & 95 \\
\hline 80 & 213 & 138 & \\
\hline
\end{tabular}


Table 3. Slot depth in $\mu \mathrm{m}$ for PMMA

\begin{tabular}{|c|c|c|c|}
\hline $\mathrm{P}(\%)$ & $\begin{array}{c}\mathrm{d}(\mathrm{um}) \mathrm{f}(50 \%) \\
\text { PMMA }\end{array}$ & $\begin{array}{c}\mathrm{d}(\mathrm{um}) \mathrm{f}(70 \%) \\
\text { PMMA }\end{array}$ & $\begin{array}{c}\mathrm{d}(\mathrm{um}) \_\mathrm{f}(100 \%) \\
\text { PMMA }\end{array}$ \\
\hline 10 & 24 & 1 & 0,3 \\
\hline 20 & 48 & 5 & 0,8 \\
\hline 30 & 105 & 14 & 8,0 \\
\hline 40 & 131 & 57 & 27,0 \\
\hline 50 & 177 & 82 & 33,0 \\
\hline 60 & 203 & 108 & 38,0 \\
\hline 70 & 247 & 147 & 45,0 \\
\hline 80 & 251 & 162 & 61,0 \\
\hline
\end{tabular}

These experimental data were evaluated and depicted in the charts.

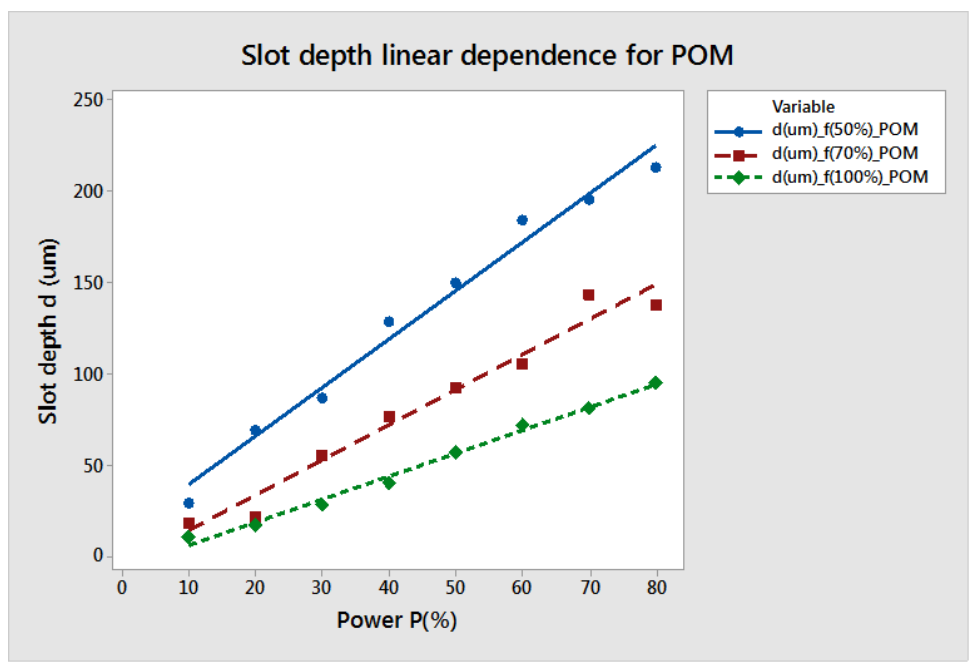

Fig. 1. Slot depth linear dependence for POM

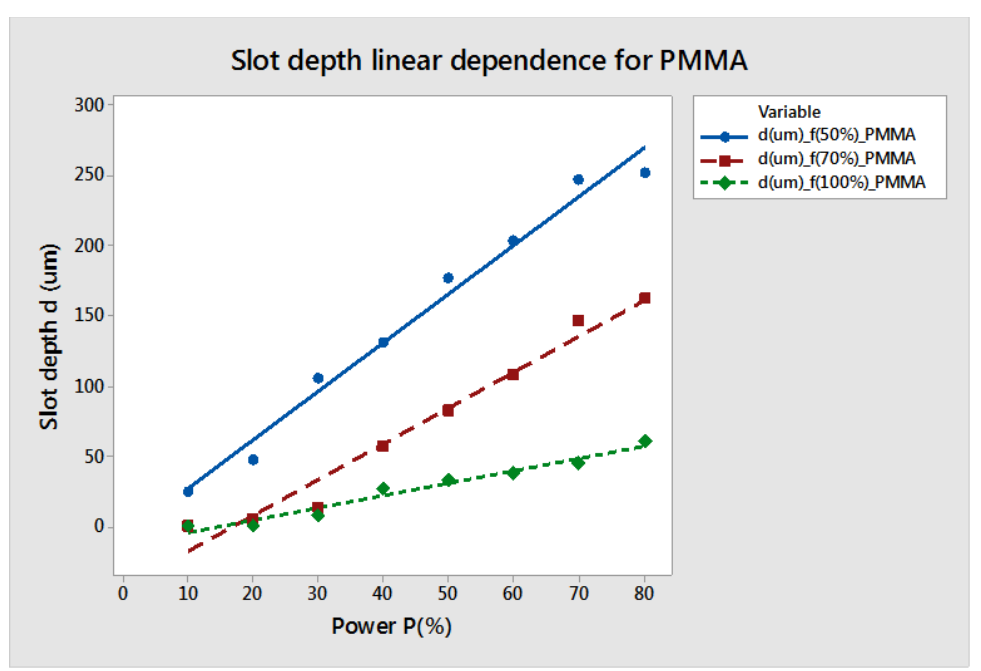

Fig. 2. Slot depth linear dependence for PMMA 


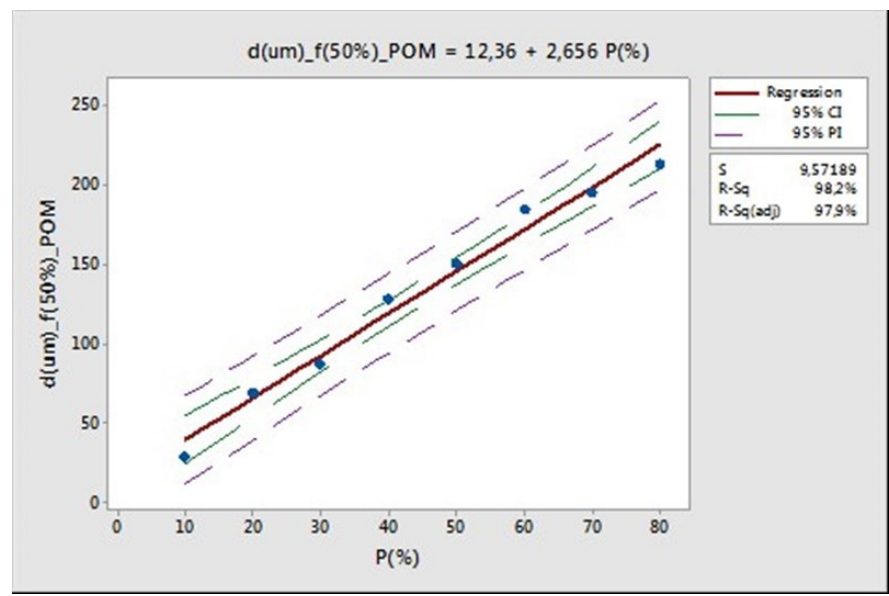

Fig. 3. Regression equation of slot depth dependencies on the laser parameters combination $\mathrm{f}(50 \%)$ for POM

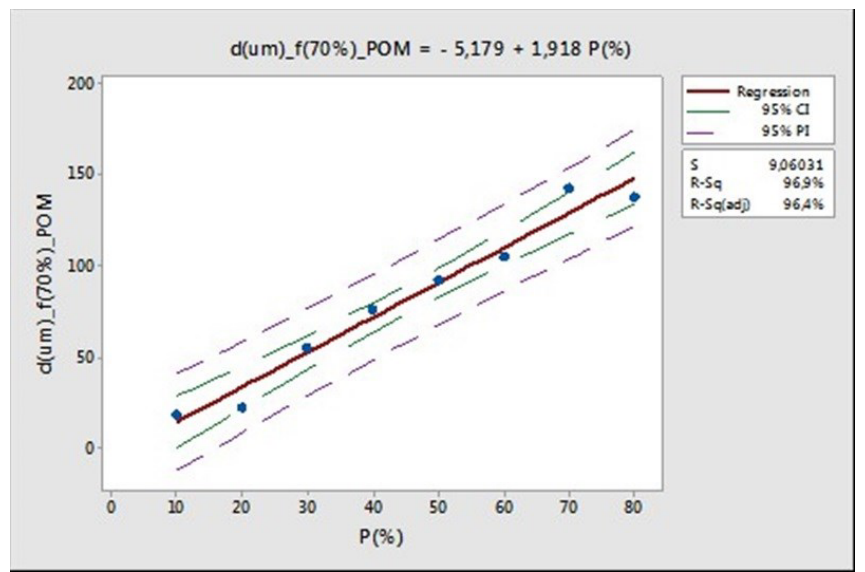

Fig. 4. Regression equation of slot depth dependencies on the laser parameters combination $\mathrm{f}(70 \%)$ for POM

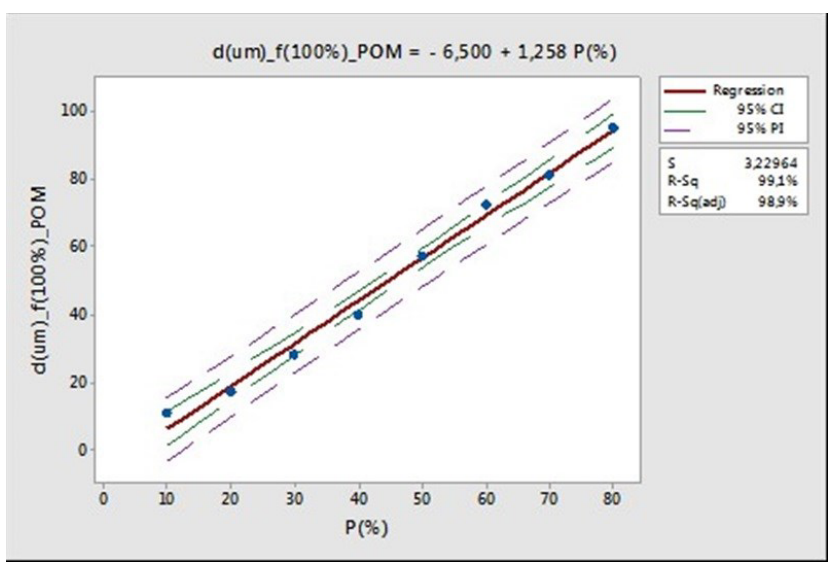

Fig. 5. Regression equation of slot depth dependencies on the laser parameters combination $\mathrm{f}(100 \%)$ for POM 


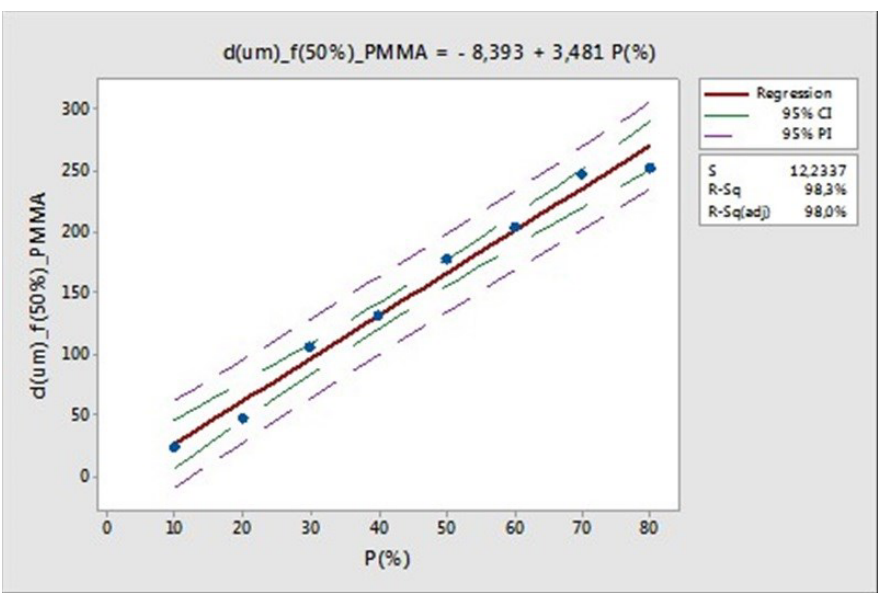

Fig. 6. Regression equation of slot depth dependencies on the laser parameters combination $\mathrm{f}(50 \%)$ for PMMA

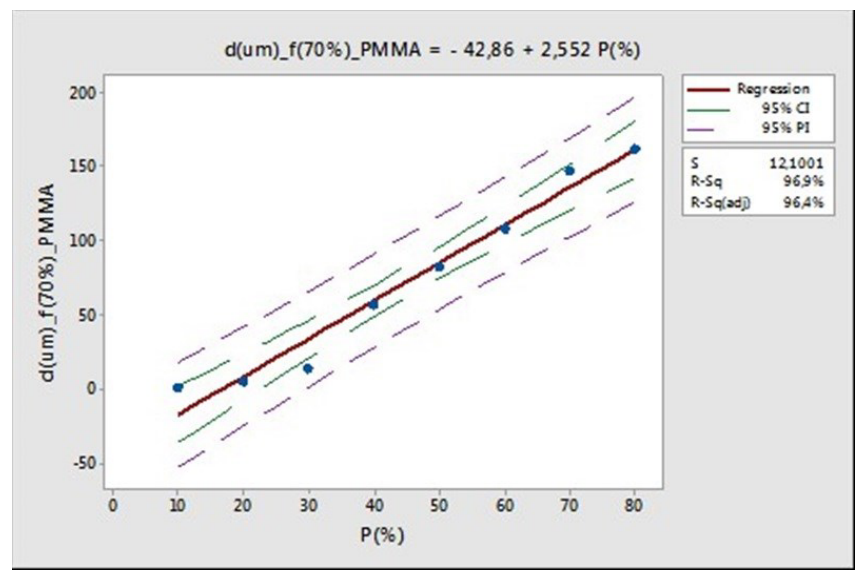

Fig. 7. Regression equation of slot depth dependencies on the laser parameters combination $\mathrm{f}(50 \%)$ for PMMA

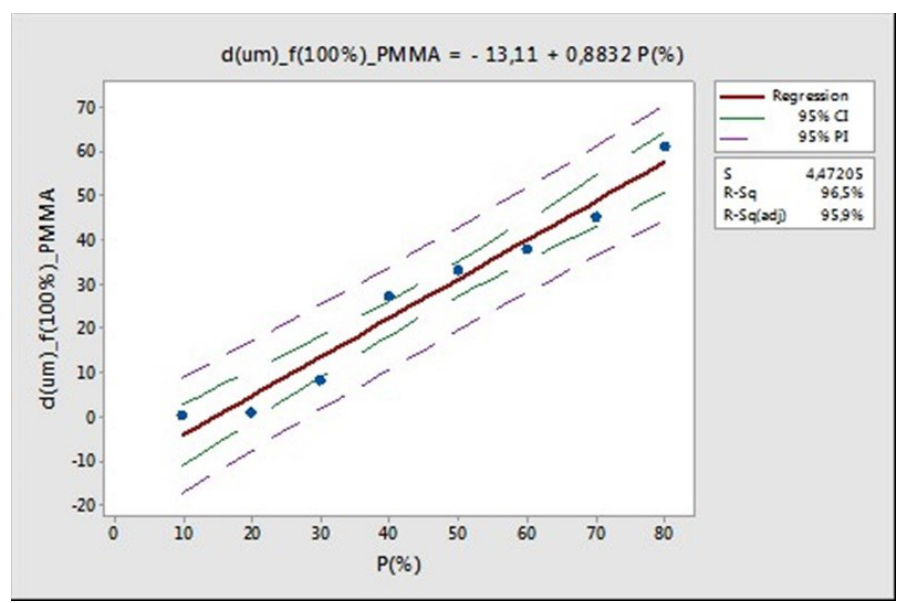

Fig. 8. Regression equation of slot depth dependencies on the laser parameters combination $\mathrm{f}(100 \%)$ for PMMA 


\section{Conclusions and Intentions}

All measured results for POM and PMMA were evaluated for the performance of P (10 $80) \%$ by the method of least squares using linear regression coefficient estimates.

For the relevant material and feed, there are listed below the corresponding regression equations, the standard deviations and determination coefficients including its adjusted form. (see Fig. 1-8)

As a result, it is evident that the slot depth grows linearly with the increasing values of power at given adjusted value of the feed. Biggest depth arises at low values of feed. This phenomenon was observed for both materials. Biggest slot depth was measured for PMMA material at the lowest speed of feed $\mathrm{f}=50 \%$, corresponding with $\mathrm{f}=533 \mathrm{mms}^{-1}$. Compared to the PMMA, regarding the crystalline polymer POM, there was bigger interaction even at the maximal speed of feed $\mathrm{f} \max =1066 \mathrm{mms}^{-1}$. Based on the detailed examination, it can be said that there was not proved either the particular effect of the different configuration of the polymer structure (amorphous vs. crystalline) or effect of different thermal conductivity on the laser machinability.

The gradient of lines and correlation coefficients offer information about dependence character of slot depth on adjusted power and feed at visible presenting results. The value of gradient $(\mathrm{k})$ is used for accurate control of stock removal (slot depth). The gradient of the line gives information about sloth depth at increasing of power about a definite number of percents. Correlation coefficient gives the relative quality of linear dependence [3].

Resulting structures can be very exact and with the high quality of surface in dependence on laser parameters and on the type of machining materials.

At the conclusion, it is possible to state that it is necessary to know output parameters combination of the particular laser system and properties of machined polymer materials for obtaining good results of micromachining by laser. It is possible to get the high accuracy of machined texture on these conditions. The result machining is different from the use of various kind of laser [4].

This work and the project is realised with the financial support of the internal grant of TBU in Zlín No. IGA/FT/2017/002 funded from the resources of specific university research.

\section{References}

1. R. Radovanovič, Strojírenská technology 9 (2004)

2. C. Felho, J. Kundrák, Characterization of Topography of Cut Surface Based on Theoretical Roughness, Key Eng. Mat., 581 (2014)

3. I. Hendl, An overview of statistical methods for data processing (Portal, Praha, 2008)

4. J. Jurko, Int. Conf. GC TECH Trencin (2002) 